\title{
Electric Field Energy Harvesting from Variable Frequency Voltage Sources for Battery-less Internet of Things
}

\author{
Oswaldo Menendez ${ }^{1}$, Loreto Romero ${ }^{1}$, and Fernando A. Auat Cheein ${ }^{1}$ \\ ${ }^{1}$ Universidad Tecnica Federico Santa Maria
}

May 5, 2020

\begin{abstract}
Internet of Things (IoT) aims to bring connectivity and integration of power system assets, focusing on active management. To ensure the reliability standards of smart cities, IoT requires a wide range of distributed network of wireless sensor nodes. However, energizing these vast networks is highly complex. This work presents a low-power system for electric field energy harvesting, focusing on smart-city applications (Urban IoTs). In particular, we examined design aspects that maximize energy harvesting efficiency according to mains frequency. Experimental findings disclose that a harvester that works at $5 \mathrm{MHz}$ can deliver up to $11 \mathrm{~mJ}$, in approximately 5 minutes. Since the leakage current of diodes is higher than harvester's current, we introduce a new management circuit, called serial switch-only rectifier (SSOR). The proposed approach is simulated and experimentally evaluated. Empirical results show that a harvester based on SSOR circuit out-performs a harvester based on a full-bridge rectifier and voltage doubler by collecting more charge, approximately $40 \%$.
\end{abstract}

\section{Hosted file}

main.pdf available at https://authorea.com/users/293366/articles/421318-electric-fieldenergy-harvesting-from-variable-frequency-voltage-sources-for-battery-less-internet-ofthings 